\title{
Robots in Special Education: Reasons for low uptake
}

\author{
M J Galvez Trigo ${ }^{1}$, P Standen², S Cobb ${ }^{3}$ \\ ${ }^{1,2}$ Division of Rehabilitation and Ageing, The University of Nottingham, Nottingham, UK \\ ${ }^{3}$ Human Factors Research Group, The University of Nottingham, Nottingham, UK \\ ${ }^{1}$ maria.galveztrigo@nottingham.ac.uk, ${ }^{2}$ p.standen@nottingham.ac.uk, ${ }^{3}$ sue.cobb@nottingham.ac.uk
}

\begin{abstract}
Purpose

This paper identifies the main reasons for low uptake of robots in Special Education, obtained from an analysis of previous studies that used robots in the area, and from interviewing Special Education teachers about the topic.

\section{Design/methodology/approach}

An analysis of 18 studies that used robots in Special Education was performed, and the conclusions were complemented and compared with the feedback from interviewing 13 Special Education teachers from Spain and UK about the reasons they believed caused the low uptake of robots in Special Education classrooms.
\end{abstract}

\section{Findings}

Five main reasons why Special Education schools do not normally use robots in their classrooms were identified: the inability to acquire the system due to its price or availability; its difficulty of use; the low range of activities offered; the limited ways of interaction offered; and the inability to use different robots with the same software.

\section{Originality/value}

Previous studies focussed on exploring the advantages of using robots to help children with Autistic Spectrum Conditions and Learning Disabilities. This study takes a step further and looks into the reasons why, despite the benefits shown, robots are rarely used in real-life settings after the relevant study ends. The authors also present a potential solution to the issues found: involving end users in the design and development of new systems using a user-centred design approach for all the components, including methods of interaction, learning activities, and the most suitable type of robots.

\section{INTRODUCTION}

Some of the first recorded uses of robots as educational tools date back to the 1980's, with a mechanical turtle used to teach Science, Technology, Engineering and Mathematics (STEM) subjects (Papert, 1983). However, the role of robots in education was first reviewed during the 1990's, with the first scientific publications highlighting the potential of this technology not only in STEM or Mainstream education, but also in Special Education and rehabilitation, mainly with a focus on children with Autism Spectrum Conditions (ASC) (Bühler, 1998; Cooper et al., 1999; Lees and Lepage, 1996). At the same time, LEGO started to market the Mindstorms robotic line in 1998; a system for inventing and building robots through a modular design and LEGO plastic bricks combined with a 'brick' computer, sensors and motors. This system is still being manufactured and used up to date.

Nowadays, educational robots are mainly used in Mainstream Education (ME) to teach STEM subjects (Armesto et al., 2015; Virnes et al., 2008). However, the use of this technology acquires special importance in the field of Special Education (SE), where studies exploring the use of robotics with children with ASC and Learning Disabilities (LD) have shown that they can be used as an effective tool to increase engagement and, consequently, goal achievement, as well as to raise interest in a specific task or subject (Andruseac et al., 2015; Standen, Brown, Hedgecock, et al., 2014; Standen, Brown, Roscoe, et al., 2014; Virnes et al., 2008). Robots used in studies with children with ASC and LD can be put into two main categories: humanoid robots and non-humanoid robots, and their prices range from around $£ 100$ to $£ 10,000$, although no price is available for some non-commercially available robots developed specifically for research studies. One of the earliest pilot studies on the use of robotics in Special Education (Karna-Lin et al., 2006), emphasised that this technology can help discover hidden skills of 
students with learning difficulties, with the potential to offer different ways of interaction and the versatility of fitting within different learning styles. However, despite the benefits that educational robots seem to offer, and the existence of studies that have tested and verified the applicability of various robots in Special Education schools, these robots do not continue to be used after the relevant study ends. This raises an important question: why? The aims of the study presented in this paper are to answer this question establishing the main reasons for lack of uptake of this technology, as well as to introduce a suggested solution to the issues found. This solution is based on working very closely with the potential users of systems used to control educational robots from the early stages of the design to the final testing to ensure application design is easier to use in a classroom setting.

\section{METHODS}

In order to discover why educational robots are not widely used, a review of previous research studies that have used robots with children with ASC or LD was first conducted. The characteristics of these studies and the systems that they used were annotated, compared, and analysed (Aslam et al., 2016; Galvez Trigo and Brown, 2014; Hedgecock et al., 2014; Standen, Brown, Hedgecock, et al., 2014; Standen, Brown, Roscoe, et al., 2014). For this analysis, information was extracted regarding: the robot used and its type (humanoid or non-humanoid); its commercial availability and price where relevant; the target user group participating in the study; the control devices that were used to operate the robot; who controlled the robot; , the availability of an interface for the final users; and finally, the type of activities included during the study. The results of this analysis can be seen in Table 2 and discussion of the findings is given in section 4. Once these data were collated, a series of informal interviews were conducted with Special Education teachers in schools situated in Spain and the United Kingdom.

\subsection{Analysis of previous studies}

Due to the changing nature of technology, especially robotics, the analysis focussed on studies carried out from the year 2000 onwards, covering studies from different countries with participants with ASC or LD.

Over this period, several studies have been reported, however, as some researchers highlight (Cho and Ahn, 2016; Pennisi et al., 2016), most of the research in this area focuses on the technical development and construction of these robots, and not on their actual testing in real-life settings. The studies reviewed have used different robots and different methods of interaction with the robots to investigate their effectiveness and effects when used with children with ASC and/or LD. Most of them reached similar conclusions, and although the conclusions were positive, none of the studies has had enough impact to be known about by SE schools and encourage them to acquire the piloted system, in those cases where the system was commercially available.

2.1.1 Eligibility criteria. Since the purpose of this study was not to offer a systematic review of the studies that have used robots in Special Education, but to find out why educational robots are not used in the classroom, the following selection criteria were applied. Studies must have been published from 2000 onwards, they must include at least a pilot with children with ASC and/or LD, they should not present repetitions or variations of the same experiment with the same system, even in different years, and they must describe the robot and system used. Based on these criteria, the analysis was applied to 18 studies that used educational robots in Special Education settings.

\subsection{Interviews with teachers}

After carrying out the review of the relevant systems, a series of interviews was conducted with teachers at three Special Education schools to discuss the reasons why they believe educational robots are not being used in the classrooms. One of these schools had already worked with the research team in previous studies.

2.2.1 The participants. The participants were teachers working in a school for children with ASC and/or LD. One of the schools was a Special Education school from UK for children aged 3 to 19, whilst the other two were a state and an independent Special Education schools in Spain, both for children aged 3 to 21. These schools were selected for several reasons. Firstly, they are all SE schools, having students with high-functioning to low-functioning ASC, MLD, SLD, as well as PMLD that in some cases are accompanied by Physical Disabilities (PD) such as Cerebral Palsy (CP), catering for a wide range of children with ASC and/or LD. Secondly, from participation in various projects that used educational robots in SE, the authors have observed that there are cultural and organisational differences in the way Special Education is approached among different countries, and including participants from two different countries provided a broader perspective, as well as to see if, despite the cultural and organisational differences, the same conclusions would be obtained. Lastly, it was important that the participants felt comfortable during the interviews, therefore, conducting them in their native language was the best option, since a member of the research team is a native Spanish speaker schools in Spain were recruited. As in Spain there are usually significant differences between state schools and independent schools, it was decided that one on each category should be recruited. After obtaining the relevant ethical approval, the head teacher of each school was presented with a summary of the proposed study, and they then invited teachers from their school to take part in the 
interviews. They circulated that information among their teachers and directed us to those that were interested in participating. A total of 13 teachers volunteered to participate in the interviews: 3 from the school in the UK, 7 from the state school in Spain, and 3 from the independent school in Spain. Participants came from different generations and backgrounds, with some having previously used robots in the classroom and some others not. Since the study was introduced to the teachers by their head teacher, it was not possible to determine the reasons why not all teachers volunteered to participate, and their personal interest on the use of these technologies in the classroom might have played an important role. However, head teachers indicated that the overall reaction to the study was very positive also among teachers that did not volunteer, and that they considered the participation high, given that most teachers had little time available. The school in the UK and the independent school in Spain had technologies such as iPads, computers, eye-trackers, and other assistive technologies. However, the state school in Spain only had computers available for some of the teachers and none for the students.

2.2.2 The interviews. With the teachers in the UK, one-to-one interviews were organised, whilst, due to time and travel restrictions, two focus group interviews were held with the teachers from the schools in Spain. During the interviews, a first introduction to the topic and past and current research was given, as well as to the robots and systems that had been used, showing them pictures and explaining to them the main characteristics of those studies. This was followed by an informal questions \& answers session where they were directed towards indicating why they believed that educational robots are not widely used in SE, and what would be their main reason for not using any of the systems that they were presented with.

\section{RESULTS}

\subsection{Analysis of previous studies}

The most relevant results obtained from the analysis of previous studies can be classified into three main categories: the robots, the methods of interaction, and the educational activities.

3.1.1 The robots. The analysis identified that 6 out of 18 studies were conducted using non-commercially available robots that were built purposely for those research studies, and none of them have become commercially available to date, with another one using both a commercially and a non-commercially available robot (Billard et al., 2007; Jimenez et al., 2016; Kozima, Nakagawa and Yano, 2005; Lathan and Malley, 2001; Marti and Giusti, 2010; Robins et al., 2003; Wainer et al., 2014). Some of these robots can be seen in Fig. 1. A major explanation regarding why those robots are not widely used in SE schools is that schools do not have access to them. Therefore, no further consideration will be given to these systems. Instead, the remainder of the review focuses on studies that used commercially available robots. Among these, the most commonly used is the robot NAO (Aslam et al., 2016; Barakova et al., 2015; Lewis et al., 2016; Shamsuddin, Yussof, Ismail, Mohamed, et al., 2012; Standen, Brown, Roscoe, et al., 2014; Warren et al., 2015), a humanoid robot manufactured by Softbank Robotics that measures $58 \mathrm{~cm}$ and offers 20-25 degrees of freedom (DoF), various sensors, and a toy-like appearance. One of the main drawbacks for use of NAO is its price, as it currently retails for a price of approximately $£ 6,000$, with retailers offering maintenance plans for additional fees. For that price, a school needs to see a very high value-for-money and have the budget available before they can decide to buy it. NAO has been used in 6 of the 12 studies that used commercially available robots, and it was most likely selected for education studies due to its friendly toy-like appearance, its capabilities, and its programmability. However, it is possible that marketing and publicity of the NAO robot, as it has been featured extensively in showcases, public events, and news reports, may have influenced interest in this specific robot type. Indeed, there are several other, more affordable robots that are very similar in appearance and features to NAO that have not been used in any published studies. Cheaper robots that have been used in other studies such as LEGO Mindstorms (a robotic kit that lets its user build a robot in different shapes and configurations using LEGO bricks, also with various sensors), used in 3 studies, and Sphero (a spherical robot that can be navigated and can produce sounds), used in 1 study, do not have as many features or capabilities as NAO. However, there is no evidence that they offer less benefits than the more expensive robots, and several studies featuring them have equally highlighted their potential in the field of SE (Golestan et al., 2017; Karna-Lin et al., 2006; Kozima, Nakagawa and Yasuda, 2005; Marti and Giusti, 2010), with a recent study comparing both types of robots finding little or no difference between their effectiveness and benefits (Aslam et al., 2016). The prices of the robots used in the studies analysed in this paper can be seen in Table 1. The reason why these robots are not widely used in SE yet may be because teachers do not see them as representing sufficient value-for-money. Some teachers might not know about the existence of some of them, and many might not know how to use them or will not have the time to spend in learning how to use them and creating activities for their students with them. Some of the commercially available robots used in the analysed studies can be seen in Fig. 2.

3.1.2 Methods of interaction. An important consideration for implementation of educational technology beyond the research study is: How and who controlled the robots during each study? If teachers, or teaching assistants, are not directly involved in the use of the technology during the research investigation, it can be very difficult - even 
impossible, for them to take up use of the technology without the support of the research and/or technical team. Analysis of the reported studies, showed that, in 12 of the 18 studies (Barakova et al., 2015; Billard et al., 2007; Jimenez et al., 2016; Kozima, Nakagawa and Yano, 2005; Kozima, Nakagawa and Yasuda, 2005; Lathan and Malley, 2001; Lewis et al., 2016; Marti and Giusti, 2010; Robins et al., 2003; Shamsuddin, Yussof, Ismail, Mohamed, et al., 2012; Standen, Brown, Roscoe, et al., 2014; Warren et al., 2015), the robot was controlled using a Wizard-of-Oz approach, relying usually on a member of the research team to remotely control the actions and responses of the robot, normally without the knowledge of children who were interacting with it. The reason for this was, most likely, that control of the robot required a separate laptop interface and knowledge of the control interface/editor or programming language used, that is different for each robot. In many cases, teachers would not possess the skills and/or time needed to operate the robot. Lack of a user-friendly interface that teachers and children can use to interact with the robot can be a decisive factor when choosing if they should or should not buy a robot, as they must be able to use it in order to benefit from it. Additionally, robot sensors were not sufficiently sensitive or reliable to pick up a child's vocal response or gestures. This meant that a Wizard-of-Oz approach had to be used for some other studies thus limiting the teacher's ability to focus on other aspects of the interaction of the children with the robot, rather having to stay behind a computer controlling its actions. Apart from those considerations, 2 of the studies that did not use a Wizard-of-Oz approach did so because the activities consisted of building and programming the robot rather than controlling it and/or interacting with it. Another aspect to consider is that most studies focus on children with high-functioning ASC and/or Mild Learning Disabilities (MLD), and only 2 of those with Severe Learning Disabilities (SLD) or Profound and Multiple Learning Disabilities (PMLD)(Aslam et al., 2016; Standen, Brown, Roscoe, et al., 2014). Children in the latter two groups could have issues if they do not have an appropriate way of interacting with the robots that adapts to their needs. These ways of interaction might include the use of different Assistive Technologies (AT) such as micro-switches, joysticks, or different sensors that could interpret their orders. Only a few studies have used this kind of controlling devices, and this can be another reason why SE schools might have decided not to acquire one of these robots, since many students would not be able to benefit from them.

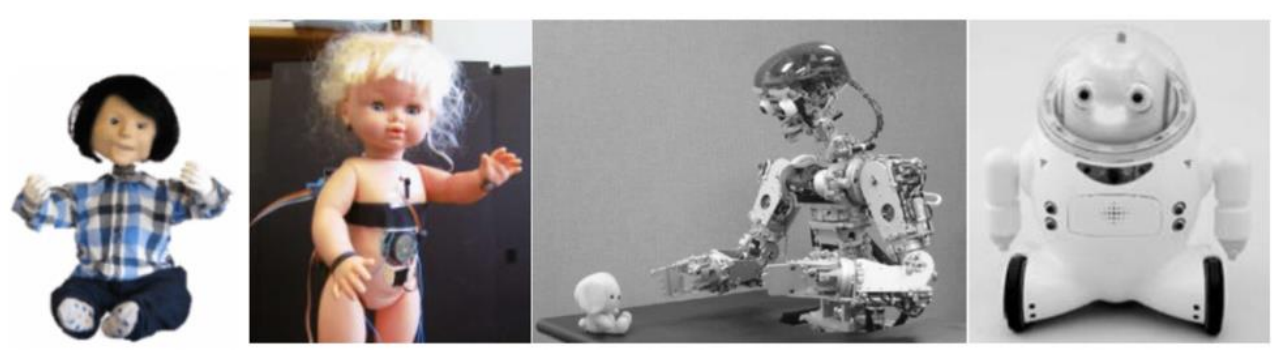

Figure 1. Some non-commercially available robots. From left to right: Kasparl, Robota ${ }^{2}$, Infanoid ${ }^{3}$, and ifbot ${ }^{4}$

3.1.3 Educational activities. The activities featured in the research studies analysed can also be seen in Table 2 . Most studies used imitation games and prompts to motivate the children to initiate a social interaction with the robot (Billard et al., 2007; Golestan et al., 2017; Kozima, Nakagawa and Yano, 2005; Kozima, Nakagawa and Yasuda, 2005; Lathan and Malley, 2001; Leo et al., 2015; Lewis et al., 2016; Robins et al., 2003; Shamsuddin, Yussof, Ismail, Mohamed, et al., 2012), however, these type of activities are more relevant for children with ASC than for children with LD, especially for those with SLD or PMLD. For these activities the children were generally able to interact independently with the robot, although supervised by a teacher, and with a researcher controlling the robot in most cases. Two of the studies involved building and programming a robot using a graphical interface (Karna-Lin et al., 2006; Virnes et al., 2008). This was reported as challenging and required more support from teachers, with some students indicating that they would prefer the use of a remote control or buttons to control the robot rather than having to program it on the given computer interface. Only a few studies included activities focused on helping the children develop other skills such as choice-making, cause and effect, or motor skills (Aslam et al., 2016; Standen, Brown, Roscoe, et al., 2014; Wainer et al., 2014). It is possible that the lack of an appropriate and wide enough range of activities might be a decisive factor for schools and teachers when deciding whether acquiring a robot will offer sufficient value-for-money.

\subsection{The teachers' views}

The results of the interviews were very consistent, with nearly all teachers showing great interest in the use of educational robots in their classrooms. Only one teacher from the independent school in Spain showed scepticism but agreed that interventions using educational robots may be beneficial for some students. Only two of the

\footnotetext{
${ }^{1}$ Reprinted by permission from Springer Nature (Huijnen et al., 2016)

${ }^{2}$ Reprinted by permission from Springer Nature (Dautenhahn and Billard, 2002)

${ }^{3}$ Reprinted by permission from Springer Nature (Kozima, 2002)

${ }^{4}$ Reprinted by permission from Springer Nature (Kanoh et al., 2004)
} 
teachers, from the UK, were involved in studies using robots in the classroom in the past or had previous experience in using this kind of robots. Most teachers were only aware of the existence of those robots with a stronger marketing presence, such as NAO and the LEGO Mindstorms, or others that they had previously seen in toys or technology retailers, with almost none of them used in previous research studies.

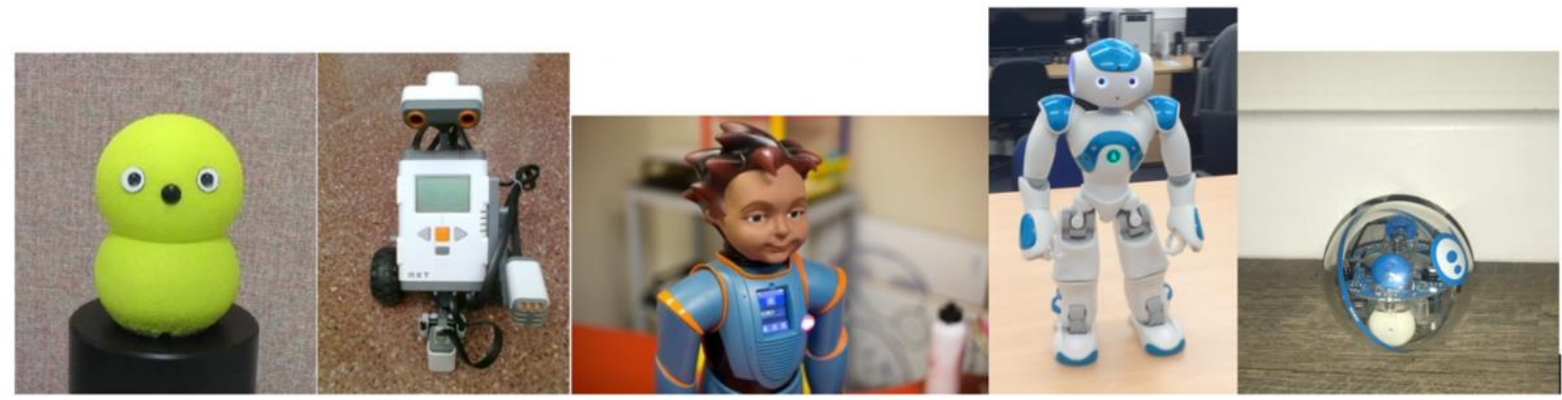

Figure 2. Some commercially available robots. From left to right: Keepon ${ }^{5}$, LEGO Mindtorms NXT', R25 Milo ${ }^{7}$, NAO robot, and Sphero

Teachers highlighted five points as the main reasons why they would not use one of the systems discussed:

- Price. The price was considered the major concern and barrier for which their school would not acquire the technology. All 13 teachers highlighted that if the school has no budget for it, it will not matter how good it is and what a great value-for-money it offers.

- Lack of a user-friendly interface. The lack of a user-friendly interface that both teachers and students could use to interact with the robot was mentioned as the second most important factor, with all 13 teachers indicating this issue as an important one.

- Lack of appropriate alternative ways of interaction for their students. Another great concern for teachers was that some students could not benefit from the use of this technology if it does not offer compatibility with alternative assistive ways of interaction, such as micro-switches, or movement-trackers. This was highlighted at first by 7 of the 13 teachers (those working with children with SLD and PMLD), although in the group interviews all teachers agreed on this point after their colleagues mentioned it, raising the number of teachers considering it an issue to 11 out of 13 teachers.

- Contents not being appropriate for their students. All 13 teachers highlighted that the contents or activities that the robot could perform would play a decisive role on whether the robot is being used or not. Some teachers mentioned that they would like to be able to create their own activities in an easy way, even if it is choosing and making combinations from a predefined set.

- Not being able to use different robots with the same controlling interface. 6 teachers (1 from the UK, 1 from the independent school in Spain and 4 from the state school in Spain) indicated that it may be necessary to use different robots to benefit a wider range of students, since a humanoid or a vehicle-like robot may not be suitable for all of them. These comments suggest that having to learn, and possibly buy, two different software systems for that purpose would be very time consuming and confusing.

Table 1. Table of prices of commercially available robots used in analysed studies

\begin{tabular}{l|l|l} 
Robot & Manufacturer & Price \\
\hline Keepon & BeatBots & $\$ 279.99(\sim £ 200)$ \\
\hline LEGO Mindstorms & LEGO & $£ 299.99$ \\
\hline R25 Milo & RoboKind & $\sim \$ 5,000(\sim £ 3,600)$ \\
\hline NAO & Softbank Robotics & $\sim £ 6,000$ \\
\hline Sphero & Sphero & $£ 119.95$ \\
\hline Topobo & Topobo Korea & $\$ 149$ to $\$ 1,250(\sim £ 107$ to £900)
\end{tabular}

\section{DISCUSSION AND CONCLUSIONS}

\footnotetext{
${ }^{5}$ Reprinted by permission from Springer Nature (Kozima et al., 2009)

${ }^{6}$ Reprinted by permission of Elsevier (Cruz-Martín et al., 2012)

${ }^{7}$ Part of the RoboKind Media kit at https://www.robokind.com/media-kit
} 
The benefits of the use of educational robots in SE are evident from the studies analysed. The teachers interviewed confirmed that they agree and would like to be able to use these robots in the classroom. However, there are still several factors that prevent schools from acquiring robots and integrating them within their curriculum.

Not being able to access the relevant robot, either because it is not commercially available, or its price is too high, is one of the main factors for non-uptake that were observed from both the analysis of previous studies and the interviews with teachers. This, together with the lack of a user-friendly interface that teachers and children could use to control the robot are the two main reasons why educational robots may not be widely used in SE schools. Teachers also commented that the range of activities that robots performed is not enough, and that more flexibility in this regard is needed, as well as more varied means of interaction for those with SLD or PMLD. Furthermore, 6 teachers mentioned during the interviews that they would like to be able to use more than one robot with just one interface, as they could try to acquire different cheaper robots instead of an expensive one if they believed that this approach would offer benefits to a larger group of students.

Table 2. Comparison table with main characteristics of the analysed studies

\begin{tabular}{|c|c|c|c|c|c|c|c|c|c|}
\hline Study & Country & User group & Robot & $\begin{array}{l}\text { Humanoid } \\
\text { robot? }\end{array}$ & $\begin{array}{l}\text { Commercially } \\
\text { available } \\
\text { robot? }\end{array}$ & $\begin{array}{l}\text { Controlling } \\
\text { devices for } \\
\text { robot }\end{array}$ & $\begin{array}{l}\text { Robot } \\
\text { controlled by }\end{array}$ & $\begin{array}{l}\text { Graphic } \\
\text { User } \\
\text { Interface } \\
\text { available } \\
\text { for users }\end{array}$ & $\begin{array}{l}\text { Type of } \\
\text { activities }\end{array}$ \\
\hline $\begin{array}{l}\text { (Lathan } \\
\text { and } \\
\text { Malley, } \\
\text { 2001) }\end{array}$ & USA & $\mathrm{PD}, \mathrm{CP}$ & GIR-T & No & No & Laptop & $\begin{array}{l}\text { Researcher, } \\
\text { children }\end{array}$ & No & $\begin{array}{l}\text { Imitation, } \\
\text { storytelling }\end{array}$ \\
\hline $\begin{array}{l}\text { (Robins et } \\
\text { al., 2003) }\end{array}$ & UK & ASC & Robota & Yes & No & Laptop & Researcher & No & Imitation \\
\hline \multirow{2}{*}{$\begin{array}{l}\text { (Kozima, } \\
\text { Nakagawa } \\
\text { and Yano, } \\
\text { 2005) }\end{array}$} & \multirow[t]{2}{*}{ Japan } & Mainstream & Infanoid & Yes & No & \multirow[t]{2}{*}{ Laptop } & \multirow{2}{*}{$\begin{array}{l}\text { Researcher. } \\
\text { Automatic } \\
\text { mode to fix } \\
\text { attention }\end{array}$} & \multirow[t]{2}{*}{ No } & \multirow{2}{*}{$\begin{array}{l}\text { Prompting } \\
\text { social } \\
\text { interaction, } \\
\text { joint attention }\end{array}$} \\
\hline & & ASC & Keepon & No & Yes & & & & \\
\hline $\begin{array}{l}\text { (Kozima, } \\
\text { Nakagawa } \\
\text { and } \\
\text { Yasuda, } \\
\text { 2005) }\end{array}$ & Japan & ASC & Keepon & No & Yes & Laptop & $\begin{array}{l}\text { Researcher. } \\
\text { Automatic } \\
\text { mode to fix } \\
\text { attention }\end{array}$ & No & $\begin{array}{l}\text { Emotion and } \\
\text { attention } \\
\text { exchange }\end{array}$ \\
\hline $\begin{array}{l}\text { (Karna- } \\
\text { Lin et al., } \\
2006)\end{array}$ & Finland & MLD & $\begin{array}{l}\text { LEGO } \\
\text { Mindstorms }\end{array}$ & No & Yes & Laptop & $\begin{array}{l}\text { Teacher, } \\
\text { children }\end{array}$ & No & $\begin{array}{l}\text { Building the } \\
\text { robot, } \\
\text { programming } \\
\text { the robot }\end{array}$ \\
\hline \multirow{2}{*}{$\begin{array}{l}\text { (Billard et } \\
\text { al., 2007) }\end{array}$} & UK & Mainstream & \multirow[t]{2}{*}{ Robota } & \multirow[t]{2}{*}{ Yes } & \multirow[t]{2}{*}{ No } & \multirow[t]{2}{*}{ Laptop } & Researcher & \multirow[t]{2}{*}{ No } & \multirow[t]{2}{*}{ Imitation } \\
\hline & France & ASC & & & & & $\begin{array}{l}\text { Automatic } \\
\text { imitation }\end{array}$ & & \\
\hline \multirow[t]{2}{*}{$\begin{array}{l}\text { (Virnes et } \\
\text { al., 2008) }\end{array}$} & \multirow[t]{2}{*}{ Finland } & \multirow{2}{*}{$\begin{array}{l}\text { ASC, } \\
\text { Behavioural, } \\
\text { Emotional } \\
\text { and Social } \\
\text { Difficulties } \\
\text { (BESD) }\end{array}$} & $\begin{array}{l}\text { LEGO } \\
\text { Mindstorms }\end{array}$ & \multirow[t]{2}{*}{ No } & \multirow[t]{2}{*}{ Yes } & Laptop & \multirow[t]{2}{*}{$\begin{array}{l}\text { Teacher, } \\
\text { children }\end{array}$} & \multirow[t]{2}{*}{ No } & \multirow{2}{*}{$\begin{array}{l}\text { Building the } \\
\text { robot, } \\
\text { programming } \\
\text { the robot }\end{array}$} \\
\hline & & & Topobo & & & Remote & & & \\
\hline $\begin{array}{l}\text { (Marti } \\
\text { and } \\
\text { Giusti, } \\
\text { 2010) }\end{array}$ & USA & $\begin{array}{l}\text { ASC, MLD, } \\
\text { PD }\end{array}$ & IROMEC & No & No & $\begin{array}{l}\text { Laptop, } \\
\text { switches on } \\
\text { robot's body }\end{array}$ & Researcher & $\begin{array}{l}\text { Yes: } \\
\text { XML- } \\
\text { based }\end{array}$ & $\begin{array}{l}\text { Turn-taking, } \\
\text { follow me }\end{array}$ \\
\hline $\begin{array}{l}\text { (Shamsud } \\
\text { din, } \\
\text { Yussof, } \\
\text { Ismail, } \\
\text { Hanapiah, } \\
\text { et al., } \\
\text { 2012) }\end{array}$ & Malaysia & ASC, MLD & $\mathrm{NAO}$ & Yes & Yes & Laptop & Researcher & $\begin{array}{l}\text { Yes: } \\
\text { Choregrap } \\
\text { he }\end{array}$ & $\begin{array}{l}\text { Prompting } \\
\text { social } \\
\text { interaction }\end{array}$ \\
\hline $\begin{array}{l}\text { (Standen, } \\
\text { Brown, } \\
\text { Roscoe, et } \\
\text { al., 2014) }\end{array}$ & UK & $\begin{array}{l}\text { ASC, } \\
\text { PMLD }\end{array}$ & NAO & Yes & Yes & $\begin{array}{l}\text { Laptop, } \\
\text { joystick, } \\
\text { micro- } \\
\text { switches, } \\
\text { smartphone }\end{array}$ & $\begin{array}{l}\text { Researcher, } \\
\text { children }\end{array}$ & Yes & $\begin{array}{l}\text { Choice- } \\
\text { making, } \\
\text { response, } \\
\text { speech, cause } \\
\text { and effect, } \\
\text { motor skills }\end{array}$ \\
\hline $\begin{array}{l}\text { (Wainer } \\
\text { et al., } \\
2014 \text { ) }\end{array}$ & UK & ASC & KASPAR & Yes & No & - & Children & No & Collaboration \\
\hline $\begin{array}{l}\text { (Warren } \\
\text { et al., } \\
\text { 2015) }\end{array}$ & USA & ASC & NAO & Yes & Yes & Laptop & Researcher & Yes & Joint attention \\
\hline $\begin{array}{l}\text { (Barakova } \\
\text { et al., } \\
2015)\end{array}$ & $\begin{array}{l}\text { The } \\
\text { Netherlands }\end{array}$ & ASC & NAO & Yes & Yes & Laptop & Researcher & Yes & $\begin{array}{l}\text { Prompting to } \\
\text { build LEGO }\end{array}$ \\
\hline
\end{tabular}




\begin{tabular}{|c|c|c|c|c|c|c|c|c|c|}
\hline $\begin{array}{l}\text { (Leo et } \\
\text { al., 2015) }\end{array}$ & Italy & ASC & R25 Milo & Yes & Yes & Laptop & Children & No & $\begin{array}{l}\text { Emotion } \\
\text { imitation }\end{array}$ \\
\hline $\begin{array}{l}\text { (Jimenez } \\
\text { et al., } \\
2016)\end{array}$ & Japan & $\begin{array}{l}\text { Non- } \\
\text { diagnosed } \\
\text { ASC, LD }\end{array}$ & Ifbot & Yes & No & Laptop & Researcher & Yes & Storytelling \\
\hline $\begin{array}{l}\text { (Lewis et } \\
\text { al., 2016) }\end{array}$ & USA & ASC, MLD & NAO & Yes & Yes & Laptop & Researcher & Yes & $\begin{array}{l}\text { Attention, } \\
\text { imitation, } \\
\text { joint attention, } \\
\text { turn-taking, } \\
\text { initiative }\end{array}$ \\
\hline \multirow[t]{2}{*}{$\begin{array}{l}\text { (Aslam et } \\
\text { al., 2016) }\end{array}$} & \multirow[t]{2}{*}{ UK } & \multirow[t]{2}{*}{$\begin{array}{l}\text { ASC, } \\
\text { PMLD }\end{array}$} & NAO & Yes & \multirow[t]{2}{*}{ Yes } & Tablet & \multirow[t]{2}{*}{ Children } & \multirow[t]{2}{*}{ Yes } & \multirow{2}{*}{$\begin{array}{l}\text { Directions, } \\
\text { listening, } \\
\text { choice- } \\
\text { making, } \\
\text { speech }\end{array}$} \\
\hline & & & $\begin{array}{l}\text { LEGO } \\
\text { Mindstorms }\end{array}$ & No & & Remote & & & \\
\hline $\begin{array}{l}\text { (Golestan } \\
\text { et al., } \\
2017 \text { ) }\end{array}$ & Iran & ASC & Sphero & No & Yes & $\begin{array}{l}\text { Smartphone, } \\
\text { tablet }\end{array}$ & Children & Yes & $\begin{array}{l}\text { Speech, } \\
\text { prompting } \\
\text { social } \\
\text { interaction }\end{array}$ \\
\hline
\end{tabular}

These issues could be addressed with the involvement of the users from an early stage in the design of the systems used in studies that use educational robots in SE. This way, the use of very expensive robots that will never be commercialised or that do not meet the requirements of children with ASC or LD could be avoided. Since teachers and parents are the ones that know these children best, it is proposed to embark with them and their children on the design of a system that uses educational robots in SE to try to produce a system that can be adopted by schools. This solution follows a study carried out in 2014, were an interface to control NAO using tablets was developed, using feedback and design suggestions given by teachers during the design process with positive results (Galvez Trigo and Brown, 2014).

It is proposed that teachers and parents will be asked about aspects of the design such as the type of robots it should be compatible with, the control devices that it should work with, and the activities to be included. Children expressing willingness to participate, for which parental consent will be obtained, will be able to take part, providing design suggestions and using the system during the different piloting stages. This will build upon current research in which young adults with LD are reviewing educational robots and offering advice to improve development of a common interface system to make it easier for teachers to control robot interaction activities designed to meet specific learning objectives for children with special educational needs. In order to achieve this, an interface to control different robots will be developed, as this will be easier to learn and use, and will offer more flexibility to set up activities with different robots. This new common interface will include activities recommended by teachers and parents, and it will be compatible with various commercially available robots that they identify as good candidates, also allowing them to interact with these robots using different control devices such as specialist switches or motion trackers.

However, it should be considered that, due to time restrictions and logistics, only Special Schools easily accessible by the research team were involved in this study, thus limiting the number of teachers that could participate. A larger study involving more teachers from different schools in several countries would be a further step to confirm if the issues found are common to more educators and whether new ones arise or not. The fact that most participants had never used an educational robot is another factor to consider, as it can affect their views regarding their potential use in the classroom and the issues that they may present.

This study and the future steps proposed carry implications not only for students and educators, but also for researchers, manufacturers, and developers of robotic systems. Engagement plays a very important role in learning, as highlighted by Iovannone (Iovannone et al., 2003). Therefore, facilitating the use of tools such as robots can have a big impact in the way teachers deliver their classes and students learn.

The future steps also include developing a set of guidelines for the design and development of robotic systems to be used in education, based on the data obtained until now and any future data collected and analysed. These guidelines will allow the developers of future systems to identify what areas or robots they should focus on, making it easier for them to develop successful and useful systems and saving them time and efforts.

Being able to develop a user-friendly system that can be used to control different robots in SE classrooms, would also impact academia, as having access to a system that does not require previous technical or programming knowledge to operate would enable fellow researchers to conduct larger and longer studies, with more reliable data obtained from a real-life setting rather than from a controlled experimental scenario.

Acknowledgements: The authors would like to thank the teachers that volunteered to participate in the interviews. 


\section{REFERENCES}

Andruseac, G.G., Adochiei, R.I., Pasarica, A., Adochiei, F.-C., Corciova, C. and Costin, H. (2015), “Training program for dyslexic children using educational robotics", 2015 E-Health and Bioengineering Conference (EHB), No. i, pp. 1-4.

Armesto, L., Fuentes-Durá, P. and Perry, D. (2015), “Low-cost Printable Robots in Education”, Journal of Intelligent and Robotic Systems: Theory and Applications, pp. 5-24.

Aslam, S., Standen, P.J., Shopland, N., Burton, A. and Brown, D. (2016), “A Comparison of Humanoid and Non-humanoid Robots in Supporting the Learning of Pupils with Severe Intellectual Disabilities", 2016 International Conference on Interactive Technologies and Games (ITAG), IEEE, pp. 7-12.

Barakova, E.I., Bajracharya, P., Willemsen, M., Lourens, T. and Huskens, B. (2015), “Long-term LEGO therapy with humanoid robot for children with ASD”, Expert Systems, Vol. 32 No. 6, pp. 698-709.

Billard, A., Robins, B., Nadel, J. and Dautenhahn, K. (2007), "Building Robota, a Mini-Humanoid Robot for the Rehabilitation of Children With Autism Building Robota , a Mini-Humanoid Robot for the Rehabilitation of Children With Autism", Assistive Technology: The Official Journal of RESNA, Vol. 19 No. 1, pp. $37-$ 41.

Bühler, C. (1998), “Robotics for rehabilitation - A European (?) perspective”, Robotica, Vol. 16 No. 5, pp. 487490.

Cho, S.-J. and Ahn, D.H. (2016), "Socially Assistive Robotics in Autism Spectrum Disorder", Hanyang Medical Reviews, Vol. 36 No. 1, p. 17.

Cooper, M., Keating, D., Harwin, W. and Dautenhahn, K. (1999), "Robots in the classroom - tools for accessible education”, Proc. AAATE Conference, IOS Press ISO Press, Vol. 6, pp. 448-452.

Cruz-Martín, A., Fernández-Madrigal, J.A., Galindo, C., González-Jiménez, J., Stockmans-Daou, C. and BlancoClaraco, J.L. (2012), "A LEGO Mindstorms NXT approach for teaching at Data Acquisition, Control Systems Engineering and Real-Time Systems undergraduate courses", Computers \& Education, Vol. 59 No. 3, pp. 974-988.

Dautenhahn, K. and Billard, A. (2002), "Games Children with Autism Can Play with Robota, a Humanoid Robotic Doll”, Universal Access and Assistive Technology, Springer London, London, pp. 179-190.

Galvez Trigo, M.J. and Brown, D.J. (2014), "Remote Operation of Robots via Mobile Devices to Help People with Intellectual Disabilities", 2014 International Conference on Interactive Technologies and Games, IEEE, pp. 1-8.

Golestan, S., Soleiman, P. and Moradi, H. (2017), "Feasibility of using sphero in rehabilitation of children with autism in social and communication skills", 2017 International Conference on Rehabilitation Robotics (ICORR), IEEE, pp. 989-994.

Hedgecock, J., Standen, P., Beer, C., Brown, D. and S. Stewart, D. (2014), "Evaluating the role of a humanoid robot to support learning in children with profound and multiple disabilities", Journal of Assistive Technologies, Vol. 8 No. 3, pp. 111-123.

Huijnen, C.A.G.J., Lexis, M.A.S. and de Witte, L.P. (2016), "Matching Robot KASPAR to Autism Spectrum Disorder (ASD) Therapy and Educational Goals”, International Journal of Social Robotics, Vol. 8 No. 4 , pp. 445-455.

Iovannone, R., Dunlap, G., Huber, H. and Kincaid, D. (2003), "Effective Educational Practices for Students With Autism Spectrum Disorders", Focus on Autism and Other Developmental Disabilities, Vol. 18 No. 3, 
pp. $150-165$.

Jimenez, F., Yoshikawa, T., Furuhashi, T., Kanoh, M. and Nakamura, T. (2016), "Effects of Collaborative Learning between Educational-Support Robots and Children who Potential Symptoms of a Development Disability”, 2016 Joint 8th International Conference on Soft Computing and Intelligent Systems (SCIS) and 17th International Symposium on Advanced Intelligent Systems (ISIS), pp. 266-270.

Kanoh, M., Kato, S. and Itoh, H. (2004), “Analyzing Emotional Space in Sensitivity Communication Robot 'Ifbot", pp. 991-992.

Karna-Lin, E., Pihlainen-Bednarik, K., Sutinen, E. and Virnes, M. (2006), “Can Robots Teach? Preliminary Results on Educational Robotics in Special Education”, Sixth IEEE International Conference on Advanced Learning Technologies (ICALT'06), pp. 319-321.

Kozima, H. (2002), “Infanoid”, in Dautenhahn, K., Bond, A., Cañamero, L. and Edmonds, B. (Eds.), Socially Intelligent Agents: Creating Relationships with Computers and Robots, Springer US, Boston, MA, pp. $157-164$.

Kozima, H., Nakagawa, C. and Yano, H. (2005), "Using robots for the study of human social development", AAAI Spring Symposium on Developmental Robotics, pp. 111-114.

Kozima, H., Nakagawa, C. and Yasuda, Y. (2005), "Interactive robots for communication-care: a case-study in autism therapy", ROMAN 2005. IEEE International Workshop on Robot and Human Interactive Communication, 2005., Vol. 2005, IEEE, pp. 341-346.

Kozima, H., Michalowski, M.P. and Nakagawa, C. (2009), “Keepon”, International Journal of Social Robotics, Vol. 1 No. 1, pp. 3-18.

Lathan, C.E. and Malley, S. (2001), "Development of a new robotic interface for telerehabilitation", Proceedings of the 2001 EC/NSF Workshop on Universal Accessibility of Ubiquitous Computing: Providing for the Elderly, pp. 80-83.

Lees, D. and Lepage, P. (1996), "Robots in Education: The Current State of the Art", Journal of Educational Technology Systems, SAGE PublicationsSage CA: Los Angeles, CA, Vol. 24 No. 4, pp. 299-320.

Leo, M., Coco, M. Del, Carcagni, P., Distante, C., Bernava, M., Pioggia, G. and Palestra, G. (2015), “Automatic Emotion Recognition in Robot-Children Interaction for ASD Treatment”, 2015 IEEE International Conference on Computer Vision Workshop (ICCVW), Vol. 2015-Febru, IEEE, pp. 537-545.

Lewis, L., Charron, N., Clamp, C. and Craig, M. (2016), “Co-Robot Therapy to Foster Social Skills in Special Need Learners: Three Pilot Studies”, in Caporuscio, M., la Prieta, F., Di Mascio, T., Gennari, R., Gutiérrez Rodrl'liguez, J. and Vittorini, P. (Eds.), Methodologies and Intelligent Systems for Technology Enhanced Learning : 6th International Conference, Springer International Publishing, Cham, pp. 131-139.

Marti, P. and Giusti, L. (2010), "A robot companion for inclusive games: A user-centred design perspective”, Proceedings - IEEE International Conference on Robotics and Automation, pp. 4348-4353.

Papert, S. (1983), Mindstorms: Children, Computers and Powerful Ideas, New Ideas in Psychology, Vol. 1, available at:https://doi.org/10.1016/0732-118X(83)90034-X.

Pennisi, P., Tonacci, A., Tartarisco, G., Billeci, L., Ruta, L., Gangemi, S. and Pioggia, G. (2016), “Autism and social robotics: A systematic review", Autism Research, Vol. 9 No. 2, pp. 165-183.

Robins, B., Dautenhahn, K. and Boekhorst, R. (2003), "Effects of repeated exposure of a humanoid robot on children with autism - Can we encourage basic social interaction skills?", Autism, Springer London, London, pp. 1-13.

Shamsuddin, S., Yussof, H., Ismail, L.I., Mohamed, S., Hanapiah, F.A. and Zahari, N.I. (2012), "Humanoid 
robot NAO interacting with autistic children of moderately impaired intelligence to augment communication skills", Procedia Engineering, Vol. 41 No. Iris, pp. 1533-1538.

Standen, P., Brown, D., Hedgecock, J., Roscoe, J., Galvez Trigo, M.J. and Elgajiji, E. (2014), “Adapting a humanoid robot for use with children with profound and multiple disabilities", Technology, Rehabilitation and Empowerment of People with Special Needs, pp. 2-4.

Standen, P., Brown, D., Roscoe, J., Hedgecock, J., Stewart, D., Galvez Trigo, M.J. and Elgajiji, E. (2014), "Engaging Students with Profound and Multiple Disabilities Using Humanoid Robots", Universal Access in Human-Computer Interaction. Universal Access to Information and Knowledge. 8th International Conference, UAHCI 2014, Held as Part of HCI International 2014. Proceedings: LNCS 8514, available at:https://doi.org/10.1007/978-3-319-07440-5_39.

Virnes, M., Sutinen, E. and Kärnä-Lin, E. (2008), “How children's individual needs challenge the design of educational robotics", Interaction Design and Children, pp. 274-281.

Wainer, J., Dautenhahn, K., Robins, B. and Amirabdollahian, F. (2014), “A Pilot Study with a Novel Setup for Collaborative Play of the Humanoid Robot KASPAR with Children with Autism”, International Journal of Social Robotics, Vol. 6 No. 1, pp. 45-65.

Warren, Z.E., Zheng, Z., Swanson, A.R., Bekele, E., Zhang, L., Crittendon, J.A., Weitlauf, A.F., et al. (2015), "Can Robotic Interaction Improve Joint Attention Skills?", Journal of Autism and Developmental Disorders, Vol. 45 No. 11, pp. 3726-3734. 